\title{
Newborn dried bloodspot screening: mapping the clinical and public health components and activities
}

\author{
Alan R. Hinman, MD, MPH $H^{1}$, Marie Y. Mann, $M D, M P H^{2}$, and Rani H. Singh, PhD, $R D^{3}$
}

\begin{abstract}
Purpose: To define components and activities of the entire Newborn Dried Bloodspot Screening process, highlighting long-term follow-upboth clinical and public health — as a basis for defining requirements for information systems to support the process. Methods: Convene a workgroup of experts involved in various aspects of Newborn Dried Bloodspot Screening and conduct an analysis of the components and activities involved, applying Business Process Analysis, part of a collaborative requirements definition process conceived by the Public Health Informatics Institute. Results: The Newborn Dried Bloodspot Screening workgroup identified four primary business processes: screening, confirmatory/diagnostic testing, transition to long-term follow-up, and intervention management (long-term follow-up). Longterm follow-up includes care coordination/ongoing treatment, continuous quality improvement, knowledge generation, and knowledge management and dissemination. In addition, the Newborn Dried Bloodspot Screening workgroup identified public health care coordination as a new and important role to assure successful long-term follow-up. This role is defined in some detail. Conclusion: Successful newborn screening systems rely on effective partnerships to ensure that there is appropriate screening, diagnosis, and follow-up. Coordinating care across multiple settings and service providers, ensuring continuity of care over time, and generating new knowledge about heritable disorders requires information systems that can fully support the process. Developing such information systems requires a clear understanding of the Newborn Dried Bloodspot Screening process and documentation of the roles and responsibilities for all involved. Business process analysis can be applied to Newborn Dried Bloodspot Screening and other child health programs to help achieve that outcome. Genet Med 2009:11(6): 418-424.
\end{abstract}

Key Words: newborn screening, health information systems, care coordination, heritable disorders, public health

In the early 1960 s, Guthrie ${ }^{1}$ showed that it was feasible to test a newborn for phenylketonuria using a heel stick blood sample collected on a filter paper. The dried bloodspot approach was widely adopted, and now all states require that newborns be tested for phenylketonuria. Subsequently, it was shown that it is

From the ${ }^{1}$ Public Health Informatics Institute, Task Force for Child Survival and Development, Decatur, Georgia; ${ }^{2}$ Maternal and Child Health Bureau, Health Resources and Services Administration, Rockville, Maryland; and ${ }^{3}$ Southeastern Regional Genetics Group, Emory University, Atlanta, Georgia.

Alan R. Hinman, MD, MPH, Public Health Informatics Institute, Task Force for Child Survival and Development, 325 Swanton Way, Decatur, GA 30030. E-mail: ahinman@taskforce.org.

Disclaimer: Opinions stated herein are those of the authors and not necessarily of the Health Resources and Services Administration or the Department of Health and Human Services.

Disclosure: The authors declare no conflict of interest.

Submitted for publication December 8, 2008.

Accepted for publication January 31, 2009.

Published online ahead of print April 14, 2009.

DOI: 10.1097/GIM.0b013e31819f1b33 feasible to screen for many other congenital and heritable conditions using a dried bloodspot. Improvements in science and technology have generated even more sensitive testing mechanisms, such as tandem mass spectrometry. This has made it possible to screen for an expanded number of conditions. ${ }^{2}$ Acknowledging advanced screening technology and increasing genetic knowledge, the Department of Health and Human Services Secretary's Advisory Committee on Heritable Disorders in Newborns and Children (ACHDNC) recommended in 2005 that newborns be screened for a core set of 29 conditions. With the exception of audiologic assessment in newborn hearing screening, screening for the core conditions is accomplished by using a dried bloodspot as the means of specimen collection.

Newborn Dried Bloodspot Screening (NDBS) is the process of collecting a heel stick blood sample onto a filter paper collection device, analyzing the specimen using approved laboratory methods, and reporting results to health care providers and families. The NDBS program is established throughout the United States to identify infants who are at high risk of particular congenital and hereditary conditions and who likely would benefit from early diagnosis and treatment. As an accepted public health activity, newborn screening programs in state public health agencies operate under policies determined at the state level. Of course, obtaining a dried bloodspot is merely the first step in a complex and long-term process that includes education, laboratory testing, diagnosis, treatment/management, and evaluation. ${ }^{3}$ Both the clinical care and public health systems play vital roles in nearly every aspect of the process - both individually and working together. Each has responsibilities regarding testing, evaluation, and followup. Smooth functioning of the NDBS system requires extended collaboration and communication among all groups involved in the care and management of a child throughout his or her lifespan.

In the United States, NDBS programs reside in state health departments, where public health officials generally are responsible for development, implementation, and oversight of newborn screening policies and procedures. For the most part, NDBS programs have followed infants from screening through diagnosis and initiation of therapy (short-term follow-up [STFU]). They rarely have followed children through treatment and transition to adulthood (long-term follow-up [LTFU]). ${ }^{4}$ Recently, ACHDNC issued a statement defining LTFU, its key features, and its major components. ${ }^{5}$ The principal goal of LTFU is to, "assure the best possible outcome for individuals with disorders identified through newborn screening." LTFU was defined as comprising assurance and provision of quality chronic disease management, condition-specific treatment, and age-appropriate preventive care throughout the individual's lifespan. The four components were defined as follows: care coordination through a medical home, evidence-based treatment, continuous quality improvement, and new knowledge discovery. The ACHDNC definition of LTFU provided the opportunity to document the scope of the NDBS process, from STFU through LTFU. This documentation could pave the way for states as they develop their LTFU programs, a task that has acquired even more importance with the passage of the "Newborn Screening Saves Lives Act of 2007 (PL 110-204)." This 
act requires that, to receive funding authorized under the act, grantees are, "... to adopt and implement the guidelines and recommendations of the Advisory Committee that are adopted by the Secretary. .."6

Most states have individual protocols for the acquisition and analysis of dried bloodspot specimens, dissemination of screening results, and the mechanism of data input and information exchange. This does not allow for the easy flow and exchange of critical information between the public and private sectors within the newborn screening system. This type of linkage is essential, particularly if LTFU is to be achieved. Therefore, current public health practice and research focuses on developing the seamless integration of clinical and public health information systems in newborn screening to increase the likelihood that every newborn receives the appropriate and requisite services.

Currently, newborn screening programs have developed information systems that support their programmatic efforts to ensure that all children are screened and followed up appropriately. These information systems typically do not include information about LTFU. At the same time, state, federal, and health industry initiatives are guiding the evolution of singlepurpose information systems into interoperable interfaces that bring disparate records within technological reach at the point of care. The ultimate goal of an integrated health information system is to improve the quality of care. The purpose of our project was to define the components and activities of the entire NDBS process as a basis for defining the requirements of information systems to support all aspects of the process, highlighting LTFU and the role of both clinical and public health providers.

\section{MATERIALS AND METHODS}

The number of people/agencies involved in the NDBS process makes it critical that information systems have the capacity and capability of providing needed information to anyone involved in the process. Identifying the requirements for information systems that support these activities begins with an analysis of WHO does WHAT with WHOM - the business processes. Although this description seems quite straightforward, most newborn screening practitioners and health professionals do not identify with the term itself. A business process has been defined as "a collection of activities that takes one or more kinds of input and creates an output that is of value to the customer."7 As a first step toward identifying the requirements for information systems to support NDBS activities, the Public Health Informatics Institute conducted a Business Process Analysis (BPA) of the NDBS process. The institute defines business process analysis as "the effort to understand an organization and its purpose while identifying the activities, participants, and information flows that enable the organization to do its work. The output of the business process analysis phase is a model of the business processes consisting of a set of diagrams and textual descriptions to be used for design or redesign of business processes." 8

To conduct the business process analysis, the Institute convened a workgroup of experts involved in various aspects of newborn screening, including clinicians, screening and diagnostics laboratorians, and health department representatives. The NDBS workgroup used the Institute's Collaborative Requirements Development Methodology to define the workflow for the NDBS process and to identify the individuals involved with guiding infants and families through the screening processboth STFU and LTFU. Members of the NDBS workgroup are listed at the end of this article.

The NDBS workgroup had two face-to-face meetings to facilitate rigorous and focused discussion regarding the scope of the NDBS program, describe the series of screening and testing events in detail, and use the Institute's methodology to define the business process matrices, context diagrams, and task flows for each event. The NDBS workgroup also participated in a series of telephonic/electronic discussions and review of documents as the iterative consensus process went forward. A small external group (including primary care providers [PCPs]) reviewed and commented on the documents before finalization.

Tools involved in the analysis were an overall conceptual diagram, business process matrices, context diagrams, and task flows. The overall conceptual diagram (Fig. 1) lays out the scope of the NDBS system. It indicates the general categories of the steps and the direction of the workflow involved in the NDBS process. Also shown are the tools involved in LTFU that include continuous quality improvement and knowledge management. Business process matrices identify the goals, objectives, business rules, triggers, task sets, inputs, outputs, and (measurable) outcomes for each business process. Figure 2 shows the general format of a business process matrix. Context diagrams are used to illustrate the participants and the flow of information within the work environment. Context diagrams consist of two graphical elements: circles and arrows. The circles represent entities (a person or group of persons who perform one or more tasks involved in the process depicted). Arrows represent transactions that involve the exchange of information among entities. Figure 3 shows the context diagram for care coordination/ongoing treatment during intervention management (LTFU). Task flow diagrams capture the basic temporal flow of tasks and the individual or groups responsible for each task. Figure 4 depicts the task flow diagram for care coordination/ongoing treatment during intervention management (LTFU). Graphical elements in a task flow diagram depict inputs, processes, and results for each step that make up a task. These elements are displayed across horizontal areas of the task flow diagram referred to as swim lanes. The swim lanes represent the individual or groups (entities) involved in each task (e.g., family, medical home). The graphical elements may remain in one swim lane, indicating that the task is confined to that person or group, or may cross two or more swim lanes, in which case the task that these elements depict can be carried out by any of the entities displayed in those swim lanes.

\section{RESULTS}

The NDBS workgroup identified four primary business processes consistent with the NDBS components identified by ACHDNC:

- Screening

- Acquire blood spot

- Routine second screen

- Requested repeat screen

- Screening testing

- Normal (in-range) results

- Abnormal (out-of-range) results

- STFU

- Confirmatory/diagnostic testing

- Transition to LTFU

- Intervention management (LTFU)

- Care coordination/ongoing treatment

- Continuous quality improvement

- Knowledge generation

- Knowledge management and dissemination

Figures 2-4 show the business process matrix, context diagram, and task flowchart associated with care coordination/ ongoing treatment during LTFU. The process is initiated based 


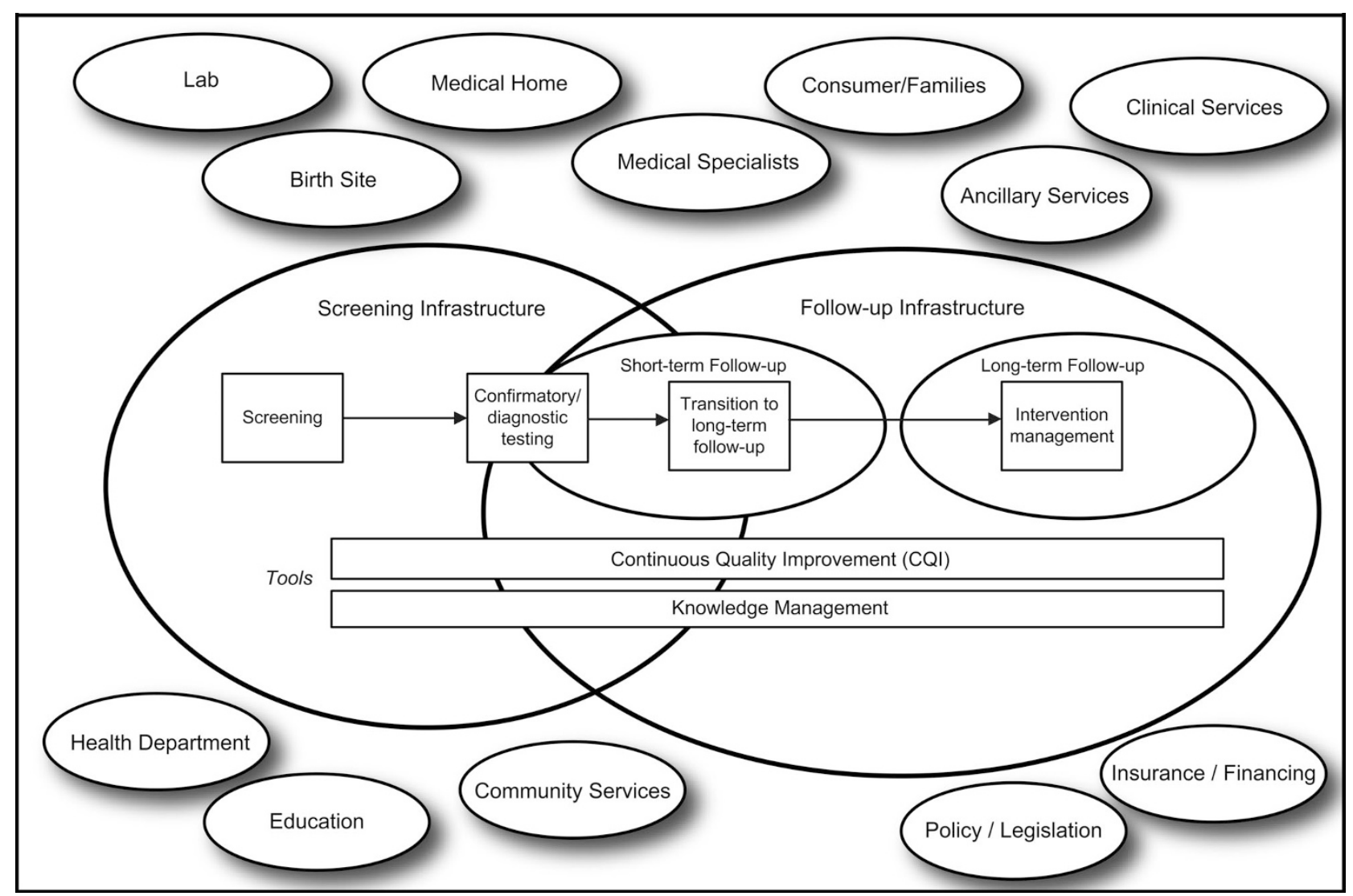

Fig. 1. Conceptual diagram, scope of NDBS program.

on the transition from STFU. As the process gets underway, the clinical team, including the PCP and specialist are involved with coordinating activities related to and ensuring effective communication among all entities involved in LTFU (Fig. 3). Activities include knowledge generation, and the entities are as follows: the family, the medical home, the laboratory, hospital, ancillary services, and the Public Health Care Coordinator (PHCC).

As shown in Figure 4, the clinical team reviews/updates the management plan, performs tests and monitors the patient, makes decisions about laboratory testing, hospitalization, and ancillary services, and interacts with the PHCC. The PHCC compiles information from several patients. Both the clinical team and the PHCC are involved in knowledge generation.

Business process matrices, context diagrams, and task flow diagrams were constructed for each of the business processes. Workgroup members felt that the process used helped them articulate the activities and information exchanges that would be required to carry out the ACHDNC-identified NBDS system components. A more complete report showing all the charts is available at www.phii.org/NDBS_BPA.

\section{DISCUSSION}

The NDBS workgroup used BPA to describe the core components and activities within the NDBS system. Defining these core activities is the initial step in defining requirements for information systems that can support the effective exchange of information among all the stakeholders involved in the overall
NDBS process, both within a state and among states. This analysis also contributes to the development of future information systems that will conform to National Health Information Network interoperability standards. The draft report of the NDBS workgroup has been shared with the work group that developed the detailed newborn screening use case for the American Health Information Community. ${ }^{9}$

Applied within the context of the NDBS system, BPA depicts the practical realities of screening by describing the responsibilities of all involved entities as well as the necessary workflow essential to the smooth and comprehensive exchange of information that can lead to a better standard of care. The NDBS workgroup sought to clarify the roles and activities conducted by public health programs, families, clinicians, ancillary services, and others. The NDBS workgroup believes that the activities described can lead to improved communication and better integration of information systems, which will in turn support comprehensive, continuous, culturally effective, and familycentered care that includes public health involvement coordinated through a medical home.

The NDBS workgroup recognized the importance of clearly outlining the steps and individuals involved with ensuring that a child is screened, appropriately diagnosed, and managed in the newborn screening system throughout his or her lifetime. Although the process was initially unfamiliar to NDBS workgroup members, they quickly grasped the potential utility to this approach and participated enthusiastically. The NDBS processes and activities leading up to the transition to LTFU were quite familiar to participants, and this is reflected in the greater 


\begin{tabular}{|c|c|c|c|c|c|c|c|c|}
\hline $\begin{array}{c}\text { Business } \\
\text { Process } \\
\text { Name }\end{array}$ & Goal & Objective & $\begin{array}{c}\text { Business } \\
\text { Rules }\end{array}$ & Trigger(s) & Task Set & Inputs & Outputs & $\begin{array}{c}\text { Measurable } \\
\text { Outcomes }\end{array}$ \\
\hline Definitions & $\begin{array}{l}\text { The major } \\
\text { goal that } \\
\text { the process } \\
\text { supports. } \\
\text { The goal is } \\
\text { the end } \\
\text { state to be } \\
\text { achieved } \\
\text { by the work } \\
\text { of the } \\
\text { agency, and } \\
\text { should } \\
\text { be defined } \\
\text { in terms of } \\
\text { the benefits } \\
\text { to the } \\
\text { community. }\end{array}$ & $\begin{array}{l}\text { A concrete statement } \\
\text { describing what the } \\
\text { business process } \\
\text { seeks to achieve. A } \\
\text { well-worded objective } \\
\text { will be SMART: } \\
\text { Specific, Measurable, } \\
\text { Attainable/Achievable, } \\
\text { Realistic, and Time } \\
\text { bound. }\end{array}$ & $\begin{array}{l}\text { A set of criteria } \\
\text { that defines or } \\
\text { constrains } \\
\text { some aspect of } \\
\text { the business } \\
\text { process. } \\
\text { Business rules } \\
\text { are intended to } \\
\text { assert business } \\
\text { structure or to } \\
\text { control or } \\
\text { influence the } \\
\text { behavior. For } \\
\text { example: laws, } \\
\text { standards, } \\
\text { guidelines, etc. }\end{array}$ & $\begin{array}{l}\text { Event, } \\
\text { action, or } \\
\text { state that } \\
\text { initiates the } \\
\text { first course } \\
\text { of action in } \\
\text { a business } \\
\text { process. A } \\
\text { trigger may } \\
\text { also be an } \\
\text { input, but } \\
\text { not } \\
\text { necessarily } \\
\text { so. }\end{array}$ & $\begin{array}{l}\text { The set } \\
\text { of } \\
\text { activities } \\
\text { that are } \\
\text { carried } \\
\text { out in a } \\
\text { business } \\
\text { process. }\end{array}$ & $\begin{array}{l}\text { Information } \\
\text { received by } \\
\text { the business } \\
\text { process from } \\
\text { external } \\
\text { sources. } \\
\text { Inputs are not } \\
\text { generated } \\
\text { within the } \\
\text { process. }\end{array}$ & $\begin{array}{l}\text { Information } \\
\text { transferred out } \\
\text { from a process. } \\
\text { The information } \\
\text { may have been } \\
\text { the resulting } \\
\text { transformation } \\
\text { of an input, or } \\
\text { it may have } \\
\text { been informa- } \\
\text { tion created } \\
\text { within the } \\
\text { business } \\
\text { process. }\end{array}$ & $\begin{array}{l}\text { The resulting } \\
\text { transaction of a } \\
\text { business process } \\
\text { that indicates } \\
\text { whether the } \\
\text { objectives have } \\
\text { been met. }\end{array}$ \\
\hline
\end{tabular}

Fig. 2. Business process matrix.

detail associated with the initial series of activities. These processes describe what is currently being done and reflect "best practices" (or, at least, "pretty darn good practices").

In accordance with the ACHDNC definition of LTFU, the NDBS workgroup identified the roles of the clinical care and PHCCs as key members of the LTFU and management of an identified child throughout his or her lifespan. Although clinical care coordination (CCC) within the medical home is generally understood, the existence and activities of the PHCC present a new definition of the role of organized public health in longterm management.

A major task of the NDBS workgroup was to build on the emerging concept of LTFU for newborn screening by describing the care coordination functions and the process of LTFU. Because the ACHDNC definition of LTFU is quite recent and because few health departments have previously played a significant role in LTFU, there is less experience with the ACHDNC-defined components of LTFU. In consequence, descriptions of the business processes associated with LTFU reflect what NDBS workgroup members thought ought to be done and therefore these might be viewed more as "aspirational practices." In particular, the definition and functions of a PHCC reflect members' views as to how the ACHDNC-defined components could most effectively be carried out. The notion of CCC is generally understood, but is variably practiced. The notion and role of a PHCC is not generally understood. There remain many unanswered questions about $\mathrm{PHCC}$, such as the organizational location, source of financing, and potential legal issues. These need to be addressed for this important new function to be carried out.

The NDBS workgroup recognized that LTFU may be somewhat different for different conditions identified through NDBS. However, they felt that the activities/roles described present a generic approach that could readily be modified as appropriate.

Care coordination is defined as "a process that links children and youth with special health care needs and their families with appropriate services and resources in a coordinated effort to achieve good health." 10 The CCC is responsible for ensuring that the affected child receives the range of appropriate services from the point of diagnosis into adulthood. As the services are provided, the CCC will evaluate the family to ensure that all needs are met, update the management plan, and provide reports to providers and relevant entities. The CCC also provides updates to the PCP, specialist, and ancillary services (this, in addition to traditional social services, may include support groups, such as those for sickle cell disease). The challenges of health care transition for adolescents with chronic conditions are well documented. ${ }^{11}$ According to the Society for Adolescent Medicine, "health care transition is most successful when there is a designated professional who, together with the patient and family, takes responsibility for the process."12

As proposed by the NDBS workgroup, the PHCC provides oversight of LTFU by monitoring the child and family's needs and assisting in addressing service gaps. This includes requesting needed services from members of the medical home and ancillary services. In describing the functions of the PHCC, the NDBS workgroup acknowledged the need for an active public health presence in fulfilling the coordination and provision of care. Overall, the PHCC assesses the completeness of care and provides assurance of the delivery of care. As the monitor of LTFU, the various activities of the PHCC as described by the NDBS workgroup are to:

- Ensure that periodic testing takes place (blood measurements, biomarkers, laboratory assessments)

- Assess whether the child is adhering to needed services

- Monitor and document the provision and coordination of services

- Coordinate information about the child and share relevant information with those entities that need the information, including the medical home, ancillary, and community services

- Assess health outcomes (including school developmental/ psychological assessments) 


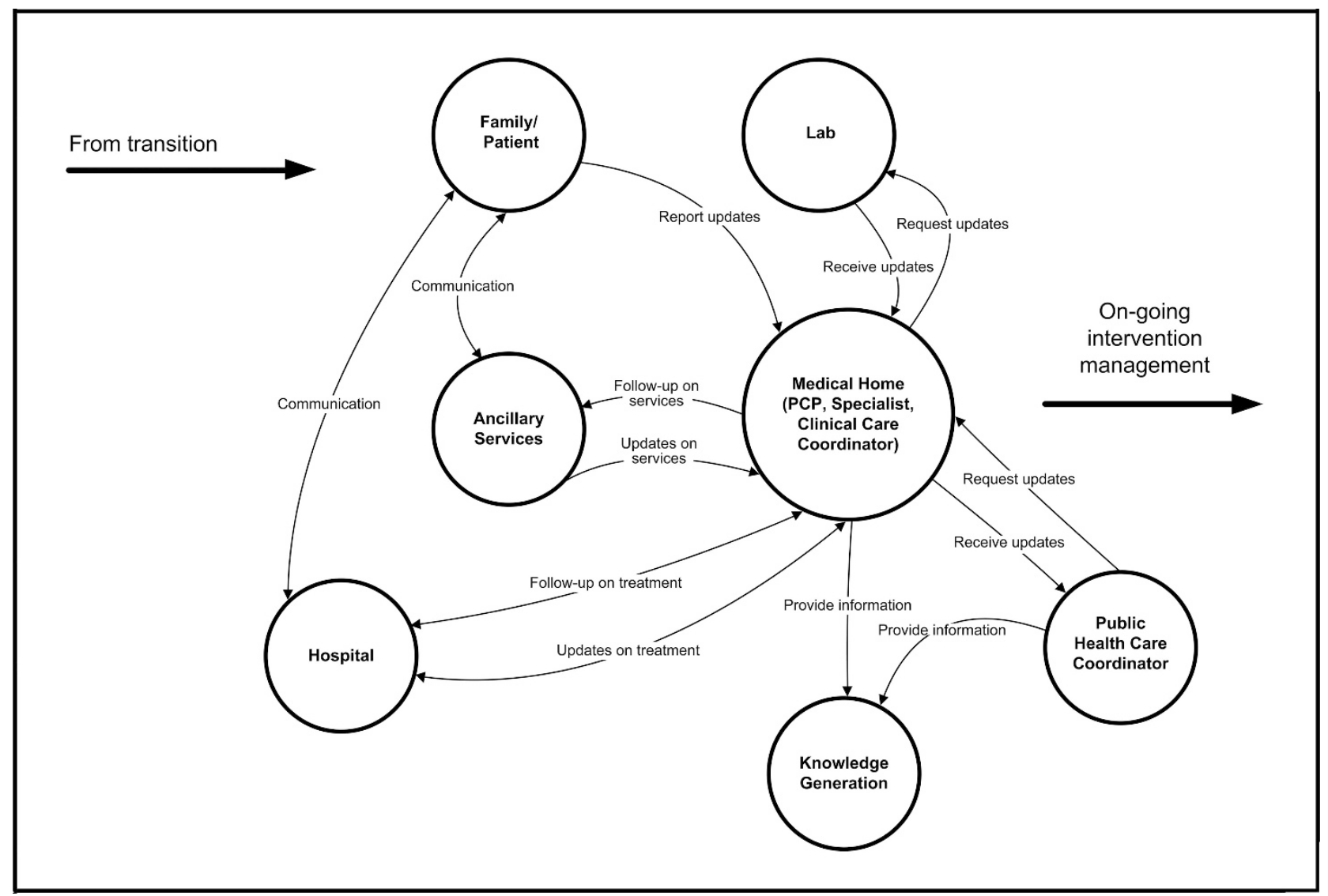

Fig. 3. Context diagram, care coordination/ongoing treatment during LTFU.

- Facilitate medical homes' timely access to test results and relevant public health information

- Report outcomes to clinicians, research entities, health plans, and community groups

- Participate in program and policy developments

The PHCC opens a case once notified of a child's abnormal result. The $\mathrm{CCC}$ and $\mathrm{PHCC}$ work closely together to monitor the care that the child receives. The CCC is actively involved in the patient's management on an ongoing, dayto-day basis, whereas the PHCC has a broad range of responsibilities.

The PHCC regularly interfaces with the CCC to gather information about the clinical services provided to the child as a means of program evaluation. The PHCC may also periodically interface with the family and assess the quality of the care that the child receives. This evaluation could take the form of a patient survey, the results of which are reported to the public health department. The PHCC uses information from the CCC, medical home, and family to update the child's management plan from the public health perspective, i.e., laboratory and ancillary services.

Both the clinical care and PHCCs are in place to provide continuity of care to the affected child and his/her family, and to ensure the consistent exchange of information among the medical home, public health entities, and ancillary services. The ultimate goal of the care coordinators is to ensure the best possible outcome for the child.
Having carried out the BPA, the next steps are to consider whether any redesign of the business process is warranted and to collaboratively develop the requirements for information systems to support the NDBS system. This work is proceeding with support from the Southeastern Regional Genetics Group and the Health Resources and Services Administration, Maternal and Child Health Bureau.

\section{SUMMARY AND CONCLUSIONS}

Successful newborn screening systems rely on effective partnerships among the family, clinical care providers, community-based systems of services, and public health programs to ensure that there is appropriate screening, followup, and timely sharing of screening results with the medical home for appropriate management and LTFU. Coordinating care across multiple settings and service providers, ensuring continuity of care over time, and generating new knowledge about heritable disorders requires information systems that can fully support the process. Developing such information systems requires a clear understanding of the NDBS system and documentation of the roles and responsibilities for all involved. By employing Business Process Analysis, we hope to have achieved that outcome. A significant result of this analysis was recognition of the importance of public health care coordination and CCC during LTFU. 


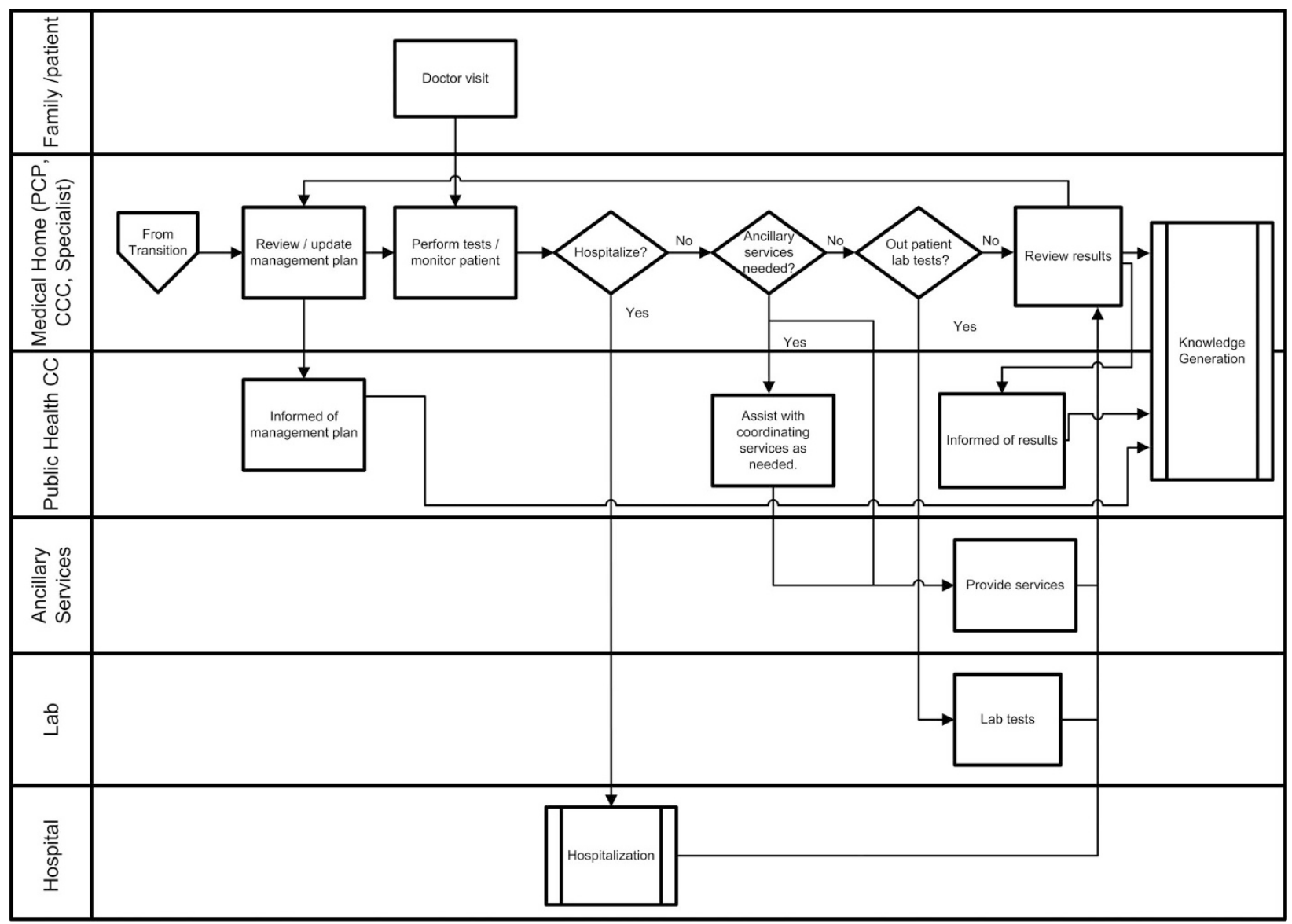

Fig. 4. Task flow diagram, care coordination/ongoing treatment during LTFU.

\section{WORKGROUP PARTICIPANTS}

\section{Partners}

Marie Y. Mann, MD, MPH, Project Officer, Maternal and Child Health Bureau, Health Resources and Services Administration; Rani Singh, PhD, RD, Associate Professor, Department of Human Genetics; Director, Metabolic Nutrition Program, Emory University School of Medicine.

\section{Workgroup members}

Ellen Amore, MS, KIDSNET Manager, Rhode Island Department of Health, Providence, RI; Bryce A. Heese, MD, Assistant Professor, Pediatric Genetics and Metabolism, University of Florida College of Medicine, Gainesville, FL; Cheryl Hermerath, MBA, DLM, (ASCP, RM [NRM]), Newborn Screening Manager, Northwest Regional Newborn Screening Program, Oregon Public Health Laboratory, Portland, OR; Gary Hoffman, Director, Newborn Screening Laboratory, Wisconsin State Laboratory of Hygiene, Madison, WI; Jan Jernell, Director, Division of Family Health, Minnesota Department of Health, St. Paul, MN; Fred Lorey, PhD, Acting Director, Genetic Disease Laboratory, California Department of Health Services, Richmond, CA; Carmen B. Lozzio, MD, FACMG, Professor, Department of Medical Genetics and Pediatrics; Clinical Geneticist, UT Genetics Center and Director of the Cytogenetics Laboratory, University of Tennessee School of Medicine, Knoxville, TN; Kimberly Noble Piper, State Genetics Coordinator, Iowa Department of Public Health, Des Moines, IA;
Bradford L. Therrell, MS, PhD, Director, National Newborn Screening and Genetics Resource Center, Austin, TX; Debra VanNostrand, RN, BSN, MEd, Metabolic Screens Coordinator, Northside Hospital, Atlanta, GA; Timothy Wood, PhD, Director, Biochemical Genetics Laboratory, Greenwood, SC.

\section{Public Health Informatics Institute staff}

Alan R. Hinman, MD, MPH, Senior Public Health Scientist; Tom Livingston, Business Analyst; Jim Mootrey, Program Manager; David Ross, ScD, Director; Srila Sen, Communications Manager, Public Health Informatics Institute, Decatur, GA.

\section{ACKNOWLEDGMENTS}

This work was supported by grants from the Health Resources and Services Administration, Bureau of Maternal and Child Health, and the Southeastern Regional Genetics Group.

\section{REFERENCES}

1. Guthrie R. Blood screening for phenylketonuria. JAMA 1961;178:863.

2. Watson MS, Mann MY, Lloyd-Puryear MA, et al. Newborn screening: toward a uniform panel and system. Executive summary. Genet Med 2006; $8: 1 \mathrm{~S}-11 \mathrm{~S}$.

3. Therrell BL, Hannon WH. National evaluation of US newborn screening system components. Ment Retard Dev Disabil Res Rev 2006;12:236-245.

4. Hoff T, Ayoob M, Tyerrell BL. Long-term follow-up data collection and use in state newborn screening programs. Arch Pediatr Adolesc Med 2007;161: 994-1000.

5. Kemper AR, Boyle CA, Aceves J, et al. Long-term follow-up after diagnosis resulting from newborn screening: statement of the U.S. Sec- 
retary of Health and Human Service's Advisory Committee on Heritable Disorders and Genetic Diseases in Newborns and Children. Genet Med 2008;1:259-261.

6. The Newborn Screening Saves Lives Act of 2007. Available at: http:// thomas.loc.gov/cgi-bin/query/z?c110:s1858. Accessed January 15, 2009.

7. Hammer M, Champy J. Reengineering the Corporation: a manifesto for business revolution. New York City: HarperCollins Publishers, Inc., 2001.

8. Public Health Informatics Institute. Taking care of business. a collaboration to define local health department business processes, 2nd ed. Decatur, GA: Public Health Informatics Institute, 2006. Available at: http://phii.org/resources/ doc/Taking\%20Care\%20of\%20Business\%2006-08.pdf. Accessed November 26, 2008.
9. American Health Information Community. Draft Detailed Newborn Screening Use Case, 2008. Available at: http://www.hhs.gov/healthit/usecases/nbs.html. Accessed November 26, 2008

10. American Academy of Pediatrics. Policy Statement. Care coordination in the medical home: integrating health and related systems of care for children with special health care needs. Pediatrics 2005;116:1238-1244.

11. American Academy of Pediatrics, Committee on Children with Disabilities and Committee on Adolescence. Transition of care provided for adolescents with special health care needs. Pediatrics 1996;98:1203-1206.

12. Society for Adolescent Medicine. Transition to adult health care for adolescents and young adults with chronic conditions. A position paper of the Society of Adolescent Medicine. J Adolesc Health 2003;33:309-311 